\title{
UNIDADE E MULTIPLICIDADE NAS CIÊNCIAS DA COMUNICAÇÃO: UMA COMPARAÇÃO ENTRE PORTUGAL E BRASIL
}

\author{
UNITY AND MULTIPLICITY IN COMMUNICATION SCIENCES: \\ A COMPARISON BETWEEN PORTUGAL AND BRAZIL
}

\section{UNIDAD Y MULTIPLICIDAD EN LAS CIENCIAS DE LA COMUNICACIÓN: UNA COMPARACIÓN ENTRE PORTUGAL Y BRASIL}

\author{
Joaquim Paulo Serra \\ Professor Associado no Departamento de Comunicação \\ pserra@ubi.pt
}

\begin{abstract}
Resumo
O observador das “ciências da comunicação" não pode deixar de constatar, desde logo, a multiplicidade conceitual, metodológica, teórica e paradigmática que as caracteriza. É certo que essa multiplicidade se verifica, também, não só no campo das ciências sociais como no das próprias ciências da natureza, umas e outras muito longe do monismo positivista de outros tempos. No entanto, longe de constituir um exemplo de "anarquismo epistemológico" (Feyerabend), essa multiplicidade das ciências da comunicação tem subjacente uma certa unidade, que lhe permite constituir-se como um campo epistémico específico. Com o objetivo de identificar traços dessa unidade nas ciências da comunicação em língua portuguesa, e assumindo que "a ciência é aquilo que se ensina" (Barthes, 2002), procedemos à análise dos currículos e programas de seis cursos de graduação considerados de referência em Portugal e no Brasil, três em cada um dos países.
\end{abstract}

Palavras-chave: Ciências da Comunicação. Portugal. Brasil.

\begin{abstract}
The observer of "communication sciences" cannot fail to notice, since the beginning, the multiple conceptual, methodological, and theoretical paradigms that characterizes them. It is true that this multiplicity also exists in the fields of the social and even the natural sciences, all of them far from the positivist monism of earlier times. However, instead of being an example of "epistemological anarchism" (Feyerabend), this multiplicity of communication sciences is based on a certain unity, which allows us to see them as an epistemic, specific field. In order to identify traits of that unity in the Communication Sciences in Portuguese language, and assuming that "science is what is taught" (Barthes, 2002), we analyzed the curricula and programs of six undergraduate, referenced courses in Portugal and Brazil, three in each country.
\end{abstract}

Keywords: Communication Sciences. Portugal. Brazil. 


\section{Resumen}

El observador de las "ciencias de la comunicación" no puede dejar de notar, desde el principio, los múltiples paradigmas conceptuales, metodológicos y teóricos que les caracterizan. Es cierto que esta multiplicidad existe también en los campos de las ciencias sociales e incluso de las naturales, todas ellas muy lejos del monismo positivista de los primeros tiempos. Sin embargo, lejos de ser un ejemplo de "anarquismo epistemológico" (Feyerabend), esta multiplicidad de ciencias de la comunicación se basa en una cierta unidad, lo que permite que sean vistas como un campo epistémico y específico. Con el fin de identificar características de la unidad en la Ciencias de la Comunicación en lengua portuguesa, y suponiendo que "la ciencia es lo que se enseña" (Barthes, 2002), se analizaron los planes y programas de seis cursos de pregrado en Portugal y Brasil, tres en cada país.

Palabras clave: Ciencias de la Comunicación. Portugal. Brasil.

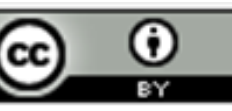

Esta obra está licenciada sob uma Licença Creative Commons

\section{O CARÁTER MULTI-PARADIGMÁTICO DAS CIÊNCIAS DA COMUNICAÇÃO}

A tradição ocidental, pelo menos desde Aristóteles, defende que a ciência se caracteriza por ser universal e necessária, ou seja, independente do contingente e do particular; e, desde Descartes, que o seu ideal é o de uma “mathesis universalis”.

Querendo-se aplicar estes critérios às ciências da comunicação, facilmente seríamos conduzidos ao seguinte dilema: ou as ciências da comunicação não são ciências; ou as ciências não são, propriamente, universais e necessárias. Ora, esta última foi, precisamente, uma das grandes descobertas da sociologia da ciência, e em particular de Thomas Kuhn (2000) e da sua teoria dos paradigmas. No entanto, também a teoria de Kuhn - e, nomeadamente, a sua ideia de que um saber só se torna científico quando nele se afirma um paradigma como dominante, quando se torna monoparadigmático - está longe de corresponder à realidade das ciências da comunicação (e não só).

De facto, como defende Serra (2008, p. 38 ss.), as ciências da comunicação devem ser consideradas como ciências multi-paradigmáticas - no sentido de que nelas confluem e coexistem, mesmo que opondo-se, múltiplos paradigmas (KUHN, 2000) e programas de investigação (LAKATOS, 1999). É certo que esta está longe de ser uma situação específica 
das ciências da comunicação, ou mesmo das ciências sociais e humanas - basta pensarmos em campos das ciências “duras” como a astrofísica ou a evolução das espécies.

Mas, levando este caráter multi-paradigmático ao limite - e esse movimento não é tão raro como isso -, poderemos ser tentados a ver as ciências da comunicação como (mais) um exemplo desse anarquismo epistemológico de que fala Paul Feyerabend (1993), e de acordo com qual “Anything goes”, isto é, se nada é (rigorosamente) científico, então tudo é “científico”.

A questão que se coloca é, portanto, a seguinte: como será possível distinguir a ciência da não ciência? Qual o critério de demarcação?

Uma das respostas possíveis a esta questão ${ }^{1}$ é a de que a ciência é, antes de mais, uma construção institucional e acadêmica. Assim, como sublinha Roland Barthes ao referir-se às ciências sociais e humanas, o que define a ciência

[...] não é nem o seu conteúdo (ele é, frequentemente, mal limitado e lábil), nem o seu método (ele varia de uma ciência para outra: o que há de comum entre a ciência histórica e a psicologia experimental?), nem a sua moral (a seriedade e o rigor não são propriedade da ciência), nem o seu modo de comunicação (a ciência é impressa nos livros, como tudo o resto), mas tão-só o seu estatuto, quer dizer, a sua determinação social: é objecto da ciência toda a matéria que a sociedade julga digna de ser transmitida. Numa palavra, a ciência é aquilo que se ensina. (BARTHES, 2002, p. 1263)

É neste sentido que se justifica, em primeiro lugar, a nossa empresa atual: identificar e comparar características definidoras dos cursos de graduação em ciências da comunicação em Portugal e no Brasil, com o objetivo de determinar o que se entende por "ciências da comunicação” em ambos os países.

\section{A CIÊNCIA E O PROBLEMA DA LÍNGUA}

Estudar o que se entende por “ciências da comunicação” em Portugal e no Brasil é estudar as ciências da comunicação que se escrevem (e dizem) em língua portuguesa. Mas que sentido tem falar da relação entre ciência e língua?

Para os fundadores da ciência moderna, a língua da ciência só pode ser a língua matemática: seja porque essa é a língua em que está escrito o "livro da natureza” (Galileu),

\footnotetext{
${ }^{1}$ Outras respostas conhecidas a esta questão, todas elas mais ou menos facilmente contestáveis, são a verificação (Carnap e o positivismo lógico), a luta contra o senso comum considerado como obstáculo epistemológico (Bachelard), ou a falsificabilidade (Popper).
} 
seja porque as línguas naturais não permitem a clareza e distinção que são apanágio da ciência (Descartes). No entanto, e porque a língua matemática não se basta a si própria, a comunicação da ciência envolve sempre, de uma ou outra forma, uma língua natural, uma língua meta-matemática.

Como é sabido, durante toda a Idade Média o latim foi a "língua franca" dos sábios. Tal permitia a livre circulação desses sábios e do seu saber - mas à custa da exclusão de todos os que não dominavam essa língua, e que eram a maioria. Para além disso, esta "língua franca” era também a língua de um conhecimento hegemónico, baseado na autoridade de Aristóteles e da Igreja, e que pretendia excluir todos os outros. O latim era, portanto, a língua de uma elite e do saber/poder dessa elite.

Compreende-se, assim, que quando os mencionados fundadores da ciência moderna tentam romper com o saber escolástico, eles tenham de romper, também, com a língua desse saber (o latim culto) - e o façam em nome de uma comunicabilidade universal (ou, pelo menos, mais alargada) da ciência.

É precisamente nesse contexto que ganham sentido as palavras que Brecht coloca na boca de Galileu: “Eu poderia escrever em vernáculo, para muitos, em vez de escrever em Latim, para uns poucos. Pois, para as novas ideias, precisamos de pessoas que trabalhem com as suas mãos.” (BRECHT, 2009, VIII-i-119). ${ }^{2}$ Algo que Galileu faz, precisamente, nas obras posteriores a Sidereus Nuncius (1610), em particular no polémico Dialogo sopre i due massimi sistemi del mondo, de 1632, escrevendo em toscano em vez de latim.

De forma análoga, Descartes justifica, no Discurso do Método, o facto de escrever em francês em vez de latim nos seguintes termos:

E se escrevo em francês, que é a língua do meu país, em vez de latim, que é a dos meus preceptores, é porque espero que aqueles que não se servem senão da sua pura razão natural ajuizarão melhor cerca das minhas opiniões do que aqueles que não acreditam senão nos livros antigos. E no que se refere àqueles que juntam o bom senso com o estudo, os únicos que desejo como meus juízes, eles não serão tão parciais em relação ao latim que recusem entender as minhas razões pelo facto de eu as explicar em língua vulgar. (DESCARTES, 1637, p. 59). ${ }^{3}$

\footnotetext{
2 "I could write in the vernacular for the many instead of in Latin for the few. For our new ideas we need people who work with their hands."

3 "Et si j’écris en français, qui est la langue de mon pays, plutôt qu'en latin, qui est celle de mes précepteurs, c'est à cause que j'espère que ceux qui ne se servent que de leur raison naturelle toute pure jugeront mieux de mes opinions que ceux qui ne croient qu'aux livres anciens. Et pour ceux qui joignent le bon sens avec l'étude, lesquels seuls je souhaite pour mes juges, ils ne seront point, je m'assure, si partiaux pour le latin, qu'ils refusent d'entendre mes raisons, pour ce que je les explique en langue vulgaire."
} 
No entanto, comunicar a ciência em vernáculo - italiano, francês, ou outra língua qualquer - acaba por determinar, também, a exclusão de todos os que não dominam cada uma dessas línguas. O ideal seria, portanto, arranjar uma língua natural que, tal como a língua matemática, pudesse ser universal e constituir a tal língua meta-matemática de que a matemática necessita.

É precisamente em nome desse suposto princípio da comunicabilidade universal da ciência que hoje se defende, tanto teórica como praticamente, o inglês - e nomeadamente o "inglês técnico" - como a nova "língua franca" da ciência. No entanto, e tal como outrora aconteceu com o latim, esta nova "língua franca", ao mesmo tempo que inclui os que a utilizam, exclui todos os - sábios e saberes - que não o fazem; e resulta, também, da hegemonia de um saber/poder, e da língua em que ele se exprime, sobre todos os outros.

Uma das principais implicações deste fato é que, cada vez mais, só a ciência que se publica (e faz) em inglês tende a merecer o estatuto de ciência - remetendo-se tudo o resto para a periferia do sistema político-científico. A saída dessa periferia só pode fazer-se mediante uma política científica que seja, simultaneamente, uma política da língua (portuguesa, neste caso).

Contribuir para essa dupla política é, precisamente, uma segunda justificação para o texto que aqui se apresenta.

\section{AS CIÊNCIAS DA COMUNICAÇÃO NO BRASIL E EM PORTUGAL}

Enquanto área acadêmica, universitária, as ciências da comunicação são uma área relativamente recente, tanto em Portugal como no Brasil - mais no primeiro caso do que no segundo.

Assim, no que se refere ao Brasil, de acordo com José Marques de Melo (2003), a área ter-se-á iniciado com a criação da primeira cátedra de Jornalismo, na Universidade do Distrito Federal, em 1935, e que foi posteriormente fechada; dando-se depois, em 1942 e 43, a criação de cursos de jornalismo no Rio de Janeiro e em S. Paulo, respectivamente (MELO, 2003, p. 155). Um momento importante, e já inserido na fase a que Marques de Melo chama de “consolidação”, foi a criação da futura Escola de Comunicações e Artes da Universidade de 
São Paulo, em 1966, com o nome de Escola de Comunicações Culturais, dotada de um corpo docente dedicado especificamente ao ensino e investigação na área das ciências da comunicação. (MELO, 2003, p. 161). Esta Escola viria a iniciar a sua atividade em Março de 1967, inaugurando o ciclo da criação das Faculdades de Comunicação no Brasil. O Programa de Mestrado em Ciências da Comunicação da ECA, que foi o primeiro da área de Comunicação do Brasil, foi criado em 8 de Janeiro de 1972. O Programa de Doutorado em Ciências da Comunicação da mesma Escola iniciou-se em 1 de Agosto de 1980. Ainda de acordo com Marques de Melo, na primeira metade da década de 90 haveria no Brasil 309 cursos de comunicação, sendo 282 de bacharelato, 22 de mestrado e 5 de doutorado (MELO, 2003, p. 165).

Quanto a Portugal, o início da área dá-se com a criação da Licenciatura em Comunicação Social, na Faculdade das Ciências Sociais e Humanas da Universidade Nova de Lisboa, em 1979. Sobretudo a partir de fins da década de 80, os cursos de comunicação social, jornalismo e ciências da comunicação multiplicaram-se pelas várias instituições de ensino superior, universitárias e politécnicas, do país - de tal modo que, e de acordo com um estudo de Mário Mesquita e Cristina Ponte, no ano letivo de 1996 existiam já, em Portugal, mais de trinta cursos, frequentados por cerca de 6500 alunos. Em matéria de pós-graduação, o primeiro curso de Mestrado em Ciências da Comunicação inicia-se na Faculdade de Ciências Sociais e Humanas da Universidade Nova de Lisboa em 1983-1984, sendo também aí apresentado, em 1990, o primeiro doutoramento na área dos estudos de comunicação (REBELO, 2002, pp. 131-2). Foi ainda na Faculdade de Ciências Sociais e Humanas da Universidade Nova de Lisboa que surgiu, em 1984, a primeira unidade de investigação na área das ciências da comunicação, o CECL - Centro de Estudos em Comunicação e Linguagens, que tem vindo a publicar, desde 1985, a Revista de Comunicação e Linguagens, que é uma das revistas da área mais antigas da Europa. ${ }^{4}$

Ao contrário do que aconteceu (e acontece) no Brasil, não há em Portugal Faculdades de Comunicação. Os cursos universitários de Comunicação constituem, no máximo, Departamentos, integrados por sua vez em Faculdades que abrigam outras áreas de estudos e Departamentos; ${ }^{5}$ essas Faculdades - também designadas “Escolas” ou “Institutos” - são, por via de regra, ou Faculdades de Ciências Sociais e Humanas (casos da Universidade Nova de

\footnotetext{
${ }^{4}$ Informações disponíveis no website da Faculdade de Ciências Sociais e Humanas.

${ }^{5}$ Uma excepção a este padrão é a Universidade de Aveiro, que não tem Faculdades, mas apenas Departamentos (incluindo o de Comunicação e Arte) e Secções Autónomas.
} 
Lisboa ou da Universidade do Minho), ou Faculdades de Letras (caso da Universidade de Coimbra) ou, ainda, Faculdades de Artes e Letras (caso da Universidade da Beira Interior). Assim, podemos dizer que, pelo menos do ponto de vista da organização e do estatuto acadêmicos, a área das ciências da comunicação está mais favorecida no Brasil do que em Portugal.

Um outro fator de distinção entre Portugal e o Brasil que merece destaque é o que se refere à duração dos cursos de graduação. No Brasil eles correspondem a "bacharelatos” e são, em regra, de 4 anos ou 8 semestres. Em Portugal, e como resultado da adequação do ensino superior ao chamado "Processo de Bolonha" a partir do ano letivo 2006/07, os cursos correspondem a "licenciaturas" de 3 anos ou 6 semestres, equivalentes a 180 créditos ECTS 6 - o que representou uma diminuição significativa na duração dos cursos, já que a generalidade tinha 4 anos, havendo mesmo alguns com $5 .^{7}$

\section{CARACTERIZAÇÃO BREVE DOS CURSOS}

Partindo do princípio de que os cursos de graduação - licenciatura em Portugal, bacharelato no Brasil - constituem a base da formação universitária, ${ }^{8}$ o estudo das suas principais características é decisivo para se entender o conceito de comunicação e de ciências da comunicação que lhes está subjacente.

Tendo em conta a conjugação de critérios como o caráter inaugural/fundador dos cursos, a localização no centro político-administrativo do país, a dispersão geográfica em cada um dos países e a avaliação dos cursos e universidades, decidimos selecionar para análise os cursos de graduação de seis universidades, três de Portugal e três do Brasil (indicam-se também as respectivas faculdades/institutos/escolas): i) Portugal: Universidade Nova de Lisboa - Faculdade de Ciências Sociais e Humanas (UNL - FCSH); Universidade do Minho - Instituto de Ciências Sociais (UM - ICS); Universidade da Beira Interior - Faculdade de Artes e Letras (UBI - FAL); ii) Brasil: Universidade de São Paulo - Escola de Comunicação

\footnotetext{
${ }^{6}$ Acrónimo de European Credit Transfer and Accumulation System.

${ }^{7}$ A duração de 5 anos era a norma aquando da criação dos primeiros cursos em Portugal, então chamados de "comunicação social” - sendo que 4 eram passados na universidade e 1 ano era dedicado ao estágio co-tutelado numa empresa de comunicação social ou outra, numa instituição pública, etc.

8 "Base" no sentido de ponto de partida do estudante que deseja dedicar-se ao ensino e/ou à investigação na área das ciências da comunicação - não ignorando que, de forma circular, a qualidade desta base está sempre dependente, em última análise, do topo, isto é, do doutoramento.
} 
e Artes (USP - ECA); Universidade de Brasília - Faculdade de Comunicação (UnB - FAC); Universidade Federal da Bahia - Faculdade de Comunicação (UFBA - FACOM).

Antes de entrarmos na análise comparativa do conteúdo desses cursos, daremos algumas indicações gerais, incluindo de cariz histórico, sobre cada um deles. ${ }^{9}$

\subsection{Universidade Nova de Lisboa}

O curso de Licenciatura em Ciências da Comunicação encontra-se integrado no Departamento de Ciências da Comunicação, que faz parte da Faculdade de Ciências Sociais e Humanas. Como referimos atrás, o curso teve o seu início no ano letivo 1979/80, inaugurando os cursos da área de ciências da comunicação em Portugal. O seu percurso típico inclui uma área geral/comum, com 120 créditos, e quatro áreas de especialização, com 30 créditos cada uma - em Cinema e Televisão, em Comunicação, Cultura e Artes, em Comunicação Estratégica e em Jornalismo -, correspondendo os outros 30 créditos a opções livres do mesmo departamento ou de outros departamentos da Faculdade de Ciências Sociais e Humanas.

\subsection{Universidade do Minho}

O curso de Licenciatura em Ciências da Comunicação encontra-se integrado no Departamento de Ciências da Comunicação, que pertence ao Instituto de Ciências Sociais (equivalente a faculdade). A então Licenciatura em Comunicação Social foi criada em Janeiro de 1991, tendo-se iniciado no ano letivo 1991/92. O curso atual inclui uma área geral, de 130 créditos, e três áreas de especialização - em Audiovisual e Multimídia, em Informação e Jornalismo e em Publicidade e Relações Públicas -, com 50 créditos cada uma.

\subsection{Universidade da Beira Interior}

O curso de Licenciatura em Ciências da Comunicação encontra-se integrado no Departamento de Comunicação e Artes, da Faculdade de Artes e Letras. O então curso de Comunicação Social foi criado em 1989 e iniciou-se em 1989/90. Atualmente conta com uma área geral com 144 créditos e três grupos de opção/especialização - em Audiovisual e Multimídia (não oferecida nos últimos anos), ${ }^{10}$ em Jornalismo e em Publicidade e Relações Públicas -, a cada um das quais correspondem 36 créditos.

\subsection{Universidade de São Paulo}

A Escola de Comunicações e Artes da Universidade de S. Paulo foi criada em 1966, com o nome de Escola de Comunicações Culturais, tendo iniciado a sua atividade em Março de 1967. Atualmente oferece as seguintes habilitações em Comunicação Social: Editoração; Jornalismo; Publicidade e Propaganda; Relações Públicas. As habilitações têm sempre uma

\footnotetext{
9 Salvo indicação específica, as informações a seguir apresentadas constam dos sites das universidades e faculdades/institutos/escolas.

${ }^{10}$ Dado que, entretanto, a Faculdade criou cursos na área do Design Multimídia e do Cinema.
} 
parte obrigatória, incluindo disciplinas comuns às várias habilitações, e uma parte opcional, sendo o número total de disciplinas variável de habilitação para habilitação.

\subsection{Universidade de Brasília}

O Curso de Comunicação encontra-se integrado na Faculdade de Comunicação. O curso teve como seu antepassado o curso de Jornalismo, criado em 1962, ano de criação da universidade. A faculdade, dita então "Faculdade de Comunicação de Massa”, seria criada em 1966. O curso atual, cujo formato se iniciou em 2003, oferece três habilitações: Audiovisual; Jornalismo; Publicidade e Propaganda. Ele implica um conjunto de disciplinas gerais e obrigatórias, comuns às três habilitações, disciplinas específicas para cada habilitação e disciplinas de opção - sendo o número total de disciplinas variável de habilitação para habilitação.

\subsection{Universidade Federal da Bahia}

A área de ciências da comunicação da Universidade Federal da Bahia teve início com a criação do curso de Jornalismo, em 1950, integrado inicialmente na Faculdade de Filosofia e, posteriormente, a partir de 1969, na Escola de Biblioteconomia e Comunicação. A atual Faculdade de Comunicação surge em 1987, integrando, para além da habilitação em Jornalismo, a habilitação em Produção em Comunicação e Cultura (VILELA; ANDRADE, 2007). Ambas as habilitações têm disciplinas obrigatórias - num total de 21 -, que são na sua maior parte comuns às duas habilitações, disciplinas específicas de cada uma das habilitações, e disciplinas optativas, num total de 7 , a escolher de entre um leque de 70 do departamento, a que se juntam 14 de outros departamentos da UFBA.

\section{5 ÁREAS DE ESPECIALIZAÇÃO / HABILITAÇÕES}

Os Quadros 1 e 2, a seguir, resumem as áreas de especialização/habilitações dos cursos de graduação que acabámos de referir:

\begin{tabular}{|l|l|l|}
\hline Universidade & $\begin{array}{l}\text { Áreas de especialização / } \\
\text { habilitações }\end{array}$ & Observações \\
\hline UNL & $\begin{array}{l}\text { Cinema e Televisão } \\
\text { Comunicação, Cultura e Artes } \\
\text { Comunicação Estratégica } \\
\text { Jornalismo }\end{array}$ & \\
\hline UM & $\begin{array}{l}\text { Audiovisual e Multimídia } \\
\text { Informação e Jornalismo } \\
\text { Publicidade e Relações Públicas }\end{array}$ & \\
\hline UBI & $\begin{array}{l}\text { Audiovisual e Multimídia } \\
\text { Jornalismo } \\
\text { Publicidade e Relações Públicas }\end{array}$ & Tem cursos em áreas específicas das artes \\
\hline USP & $\begin{array}{l}\text { Editoração } \\
\text { Jornalismo } \\
\text { Publicidade e Propaganda }\end{array}$ & Tem cursos nas áreas específicas das artes \\
\hline
\end{tabular}

ANIMUS R. Interamericana de Comunicação Midiática, http://www.ufsm.br/revistas E-ISSN 2175-4977, v. 11, n. 21, Jan-Jun(2012) 


\begin{tabular}{|l|l|l|}
\hline & Relações Públicas & \\
\hline UnB & $\begin{array}{l}\text { Audiovisual } \\
\text { Jornalismo } \\
\text { Publicidade }\end{array}$ & \\
\hline UFBA & $\begin{array}{l}\text { Jornalismo } \\
\text { Produção em Comunicação e } \\
\text { Cultura }\end{array}$ & $\begin{array}{l}\text { Tem cursos de artes interdisciplinares, com outras } \\
\text { faculdades da UFBA }\end{array}$ \\
\hline
\end{tabular}

Quadro 1: Universidades por áreas de especialização/habilitações

\begin{tabular}{|l|l|}
\hline Áreas de especialização / habilitações & Universidade \\
\hline Audiovisual & UnB \\
\hline Audiovisual e Multimídia & UM \\
& UBI \\
\hline Cinema e Televisão & UNL \\
\hline Comunicação Estratégica & UNL \\
\hline Comunicação, Cultura e Artes & UNL \\
\hline Editoração & USP \\
\hline Jornalismo / Informação e Jornalismo & UNL \\
& UBI \\
& USP \\
& UnB \\
& UFBA \\
UM \\
\hline Produção em Comunicação e Cultura & UFBA \\
\hline Publicidade & UnB \\
\hline Publicidade e Propaganda & USP \\
\hline Publicidade e Relações Públicas & UM \\
& UBI \\
\hline Relações Públicas & USP \\
\hline
\end{tabular}

Quadro 2. Áreas de especialização/habilitações por universidade

Como se pode observar nos Quadros 1 e 2, aquilo que é comum a todas as universidades consideradas é a área de especialização/habilitação em Jornalismo (ainda que, no caso da UM, ele se chame Informação e Jornalismo). Nas outras áreas de especialização/habilitações existe uma variação maior ou menor, a começar logo pelos respectivos nomes.

Assim, e no domínio do que poderíamos chamar comunicação persuasiva/instrumental, a UNL opta por Comunicação Estratégica, que engloba marketing, publicidade, relações públicas, comunicação institucional, comunicação política, etc.; a UM e a UBI optam por juntar Publicidade e Relações Públicas; a USP, por sua vez, separa estas duas áreas, juntando no entanto a Publicidade e a Propaganda; a UnB só tem Publicidade; a UFBA não tem esta área. De referir, ainda, que nas universidades brasileiras, e diferentemente do que acontece nas portuguesas, as áreas de Publicidade e de Relações Públicas existem separadas. 
No domínio daquilo a que poderíamos chamar a comunicação pela imagem, a variação também é a regra, Assim, temos Audiovisual na UnB, Audiovisual e Multimídia na UM e na UBI, Cinema e Televisão na UNL; a área não existe na USP e na UFBA, quiçá pelo facto de terem cursos nas áreas das artes, incluindo as chamadas "artes visuais”.

No domínio específico da comunicação e cultura, compreendendo a produção de bens culturais, a área apenas existe na UNL (Comunicação, Cultura e Artes), na UFBA (Produção em Comunicação e Cultura) e na USP (Editoração).

\section{ESTRUTURA CURRICULAR}

A estrutura curricular dos cursos analisados contempla um conjunto de disciplinas que se podem caracterizar a partir das dicotomias seguintes (sendo que as do primeiro par da dicotomia tendem a concentrar-se nos primeiros anos e as do segundo par nos anos mais avançados):

I. Disciplinas de caráter obrigatório e disciplinas de caráter opcional, com peso e em número variáveis, e que podem corresponder ou não - mas em geral correspondem - às áreas de especialização/habilitações. Nalguns casos, estas disciplinas podem ser cursadas noutros departamentos da faculdade ou mesmo da universidade.

II. Disciplinas de caráter mais teórico (com a designação “Teoria de...”, mas não só) e outras de caráter mais prático, correspondendo a "ateliês", “oficinas” ou "laboratórios”, e incluindo a produção de bens comunicacionais/culturais.

III. Disciplinas de caráter mais geral (Semiótica, Teoria da Comunicação, etc.) e disciplinas de caráter mais específico (Jornalismo Online, Assessoria de Imprensa, etc.).

Refira-se, ainda nesta matéria, uma distinção que para nós é essencial: no caso do Brasil, o curso de graduação termina com um TCC (UFBA) ou Projeto (UnB e USP), que ocupa praticamente todo o último semestre e pode mesmo começar a ser preparado antes dele. Em Portugal, esta prática é apenas seguida pela UM, que não lhe concede, no entanto, o peso que tem no Brasil (o Projeto da UM compreende 14 créditos, sendo que o total de um semestre equivale a 30 créditos). 


\section{7 ÁREAS DISCIPLINARES}

Como vimos atrás, todos os cursos analisados contemplam um conjunto de disciplinas de caráter geral, em regra obrigatórias para todas as áreas de especialização/habilitações - de cujo conjunto se excluem, por conseguinte, as disciplinas específicas das áreas de Jornalismo, Publicidade, etc., que tendem a ser mais ou menos idênticas nas áreas de especialização/habilitações homónimas, bem como as de caráter opcional, que se torna muito difícil comparar. Tomando como referência e ponto de partida o elenco dessas disciplinas obrigatórias na UNL, analisámos a situações dos cursos das restantes universidades com o objetivo de identificar áreas científicas comuns. O resultado pode ver-se no Quadro 3, a

\begin{tabular}{|l|l|l|l|l|l|l|l|}
\hline Disciplinas (*) & UNL & UM & UBI & USP & UnB & UFBA & TOTAL \\
\hline Comunicação e Ciências Sociais & $\mathrm{X}$ & & & & & & 1 \\
\hline Direito e Deontologia da CS & $\mathrm{X}$ & $\mathrm{X}$ & $\mathrm{X}$ & $\mathrm{X}$ & $\mathrm{X}$ & $\mathrm{X}$ & 6 \\
\hline Discurso dos Media & $\mathrm{X}$ & & & & & & 1 \\
\hline Economia & $\mathrm{X}$ & & & $\mathrm{X}$ & & & 2 \\
\hline Filmologia & $\mathrm{X}$ & & & & & & 1 \\
\hline Filosofia da Comunicação & $\mathrm{X}$ & & & & & & 1 \\
\hline História dos Media & $\mathrm{X}$ & $\mathrm{X}$ & $\mathrm{X}$ & & & & 3 \\
\hline Mediação dos Saberes & $\mathrm{X}$ & & & & & & 1 \\
\hline Métodos Quantitativos & $\mathrm{X}$ & $\mathrm{X}$ & $\mathrm{X}$ & $\mathrm{X}$ & $\mathrm{X}$ & $\mathrm{X}$ & 6 \\
\hline Mutação dos Media & $\mathrm{X}$ & & & & & & 1 \\
\hline Retórica e Argumentação & $\mathrm{X}$ & & $\mathrm{X}$ & & & & 2 \\
\hline Semiótica & $\mathrm{X}$ & & $\mathrm{X}$ & & & $\mathrm{X}$ & 3 \\
\hline Sistémica e Modelos de Informação & $\mathrm{X}$ & & & & & & 1 \\
\hline Sociologia da Comunicação & $\mathrm{X}$ & $\mathrm{X}$ & $\mathrm{X}$ & $\mathrm{X}$ & $\mathrm{X}$ & $(\mathrm{X})$ Op. & $5(6)$ \\
\hline Teoria da Comunicação & $\mathrm{X}$ & $\mathrm{X}$ & $\mathrm{X}$ & $\mathrm{X}$ & $\mathrm{X}$ & $\mathrm{X}$ & 6 \\
\hline Teoria da Imagem e da Representação & $\mathrm{X}$ & & $\mathrm{X}$ & & $\mathrm{X}$ & & 3 \\
\hline Teoria da Notícia & $\mathrm{X}$ & & & & & & 1 \\
\hline Teoria Política & $\mathrm{X}$ & $(\mathrm{X})$ Op. & $\mathrm{X}$ & $\mathrm{X}$ & $\mathrm{X}$ & $\mathrm{X}$ & $5(6)$ \\
\hline Teorias do Drama e do Espectáculo & $\mathrm{X}$ & & & & & & 1 \\
\hline Textualidades & $\mathrm{X}$ & & & & & & 1 \\
\hline TOTAL (**) & 10 & $5(6)$ & 9 & 6 & 6 & $5(6)$ & \\
\hline
\end{tabular}

seguir:

Quadro 3: Disciplinas obrigatórias, por universidade

(*) Optou-se por considerar como idênticas as disciplinas que, apesar de terem nomes diferentes, se enquadram nas mesmas áreas científicas. Nalguns casos, os cursos têm mais do que uma disciplina nas áreas consideradas (por exemplo Teoria da Comunicação I e II).

$\left({ }^{* *}\right)$ Total das disciplinas que são partilhadas pelo menos por uma outra universidade.

O Quadro 3 permite verificar que, nas disciplinas obrigatórias, existem três áreas que, com um ou outro nome, incluindo uma ou várias disciplinas, são comuns a todas as universidades consideradas: Direito e Deontologia da Comunicação; Metodologia; Teoria da

ANIMUS R. Interamericana de Comunicação Midiática, http://www.ufsm.br/revistas E-ISSN 2175-4977, v. 11, n. 21, Jan-Jun(2012) 
Comunicação. Existem ainda duas áreas que são comuns a cinco universidades, existindo na sexta como disciplinas de opção: Sociologia da Comunicação; Teoria Política.

Numa segunda linha, a aparecerem representadas em pelo menos três das universidades, temos História dos Media (todas as de Portugal), Semiótica (UNL, UBI e UFBA) e Teoria da Imagem e da Representação (UNL, UBI e UnB).

Outro dado interessante é o referente ao total de disciplinas que cada universidade partilha com pelo menos uma das outras - e que é maior no caso da UNL (10 disciplinas), seguindo-se-lhe a UBI (9 disciplinas), verificando-se nas restantes 6 disciplinas ou 5 mais uma de opção.

\section{CONSIDERAÇÕES FINAIS}

Os principais fatores de unidade entre as universidades de Portugal e do Brasil que foram estudadas são, no que se refere às áreas de especialização/habilitações, a existência de uma área de Jornalismo em todas elas - o que se compreende não só pelo facto de ela ter sido a primeira área das ciências da comunicação a ter estatuto universitário (no caso do Brasil), mas também pelo peso que ela continua a ter nas nossas sociedades.

Em termos de estruturas curriculares, e apesar de a regra ser a semelhança, há uma diferença relevante: o caráter mais projetual dos cursos no Brasil, materializado num TCC ou num Projeto final, e que não existe ou existe de forma muito limitada nos cursos de Portugal. Uma das consequências desta inexistência, ditada em grande medida pela redução dos cursos de quatro para três anos imposta pelo chamado "Processo de Bolonha”, é a de que estudantes portugueses chegam ao mestrado sem terem passado por um trabalho autónomo, de fundo, no domínio da investigação e/ou criação - o que não deixa de ser contraditório com aqueles que são alguns dos objetivos proclamados do referido "Processo de Bolonha” (o "ensino centrado no aluno", a “autonomia”, etc.). 
Já quanto às áreas disciplinares, e para além de toda a diversidade que existe, existem seis disciplinas que se destacam pela pertença comum: Direito e Deontologia da Comunicação, Metodologia e Teoria da Comunicação, que são as três comuns a todas as universidades; Sociologia da Comunicação e Teoria Política, que são comuns a cinco universidades, existindo na sexta como disciplinas de opção. Este conjunto de disciplinas constitui, assim, o "núcleo duro” teórico, básico, dos cursos de ciências da comunicação estudados, em Portugal e no Brasil.

\section{REFERÊNCIAS}

BARTHES, R. De la science à la littérature. In Oeuvres Complètes, Tome II. Paris: Éditions du Seuil, 2002.

BRECHT, B. The life of Galileo Galileo. Brecht Estate and Susanne Spirit, Corona, CA, 2009. Disponível em

$<$ http://web.me.com/greenlandglobal/Galileo/Introduzione_files/galileowebtext.pdf $>$. Acesso em: 15 jul. 2011.

DESCARTES, R. Discours de la méthode (1637). Disponível em: <http://www.acgrenoble.fr/PhiloSophie/file/descartes_methode.pdf>. Acesso em: 7 Jun. 2011.

FEYERABEND, P. K. Contra o Método. Lisboa: Relógio D’ Água, 1993.

HOHLFELDT, A. \& VALLES, R. R.. Conceito e história do jornalismo brasileiro na “Revista de Comunicação”. Porto Alegre: Edipucrs, 2008.

KUHN, T. S. A estrutura das revoluções científicas. S. Paulo: Perspectiva, 2000.

LAKATOS, I. Falsificação e metodologia dos programas de investigação científica. Lisboa: Edições 70, 1999.

MELO, J. M. História do pensamento comunicacional. S. Paulo: Paulus, 2003.

REBELO, J. Da comunicação social às ciências da comunicação. Breve análise crítica de duas décadas de ensino e de investigação. In: MIRANDA, J. A. B.; SILVEIRA, J. F. (Org.). As ciências da comunicação na viragem do século - Actas do I Congresso da Associação Portuguesa de Ciências da Comunicação. Lisboa: Vega, 2002.

ROMANCINI, R. O campo científico da comunicação no Brasil: institucionalização e capital científico. Tese de doutoramento, Escola de Comunicação e Artes, Universidade de São Paulo, S. Paulo, 2006. 
SERRA, P. Manual de teoria da comunicação. Covilhã: Livros Labcom, 2006.

VILELA, C. \& Andrade, G.. História da Facom, 2007. Disponível em:

<http://www.facom20anos.ufba.br/txt-historico.html>. Acesso em: 27 maio 2011.

\section{WEBSITES DAS UNIVERSIDADES ${ }^{11}$}

Universidade Nova de Lisboa - www.unl.pt

Universidade do Minho - www.uminho.pt

Universidade da Beira Interior - www.ubi.pt

Universidade de São Paulo - www4.usp.br

Universidade de Brasília - www.unb.br

Universidade Federal da Bahia - www.ufba.br

Original recebido em: 01/11/2011

Aceito para publicação: 10/07/2012

Resumo sobre o autor

J. Paulo Serra é Licenciado em Filosofia pela Faculdade de Letras de Lisboa e Mestre, Doutor e Agregado em Ciências da Comunicação pela Universidade da Beira Interior. Nesta Universidade, é Professor Associado no Departamento de Comunicação e Artes e investigador no Laboratório de Comunicação e Conteúdos On-line (LABCOM), integrando o Grupo de Investigação sobre Informação e Persuasão. Desempenha, atualmente, os cargos de Presidente da Faculdade de Artes e Letras e de Director do Doutoramento em Ciências da Comunicação. É autor dos livros A Informação como Utopia (1998), Informação e Sentido: O Estatuto Epistemológico da Informação (2003) e Manual de Teoria da Comunicação (2008), co-autor do livro Informação e Persuasão na Web. Relatório de um Projecto (2009) e co-organizador das obras Jornalismo Online (2003), Mundo Online da Vida e Cidadania (2003), Da comunicação da Fé à fé na Comunicação (2005), Ciências da Comunicação em Congresso na Covilhã (Actas, 2005), Retórica e Mediatização: Da Escrita à Internet (2008), Pragmática: Comunicação Publicitária e Marketing (2011) e Filosofias da Comunicação (2011). Tem ainda vários capítulos de livros e artigos publicados em obras coletivas e revistas. A sua investigação tem incidido, prioritariamente, nos processos de informação e persuasão relativos à comunicação mediática, com especial ênfase na que se refere à Internet.

\footnotetext{
${ }^{11}$ Consultados ao longo do mês de Julho de 2011.
} 